\title{
Fundamentos da geopolítica neo-eurasianista na inserção russa no caso sírio
}

\section{Fundamentals of the neo-eurasianist geopolitics in the russian insert in the Syrian case}

\section{THAINÁ PENHA BAIMA VIANA NUNES MAYANE BENTO SILVA}

\section{INTRODUÇÃO}

Após o fim da União Soviética, a Rússia se viu diante de muitos desafios. Um deles foi a reconstrução de sua geopolítica histórica e indispensável para muitos dos atos russos ao longo dos últimos dois séculos. Motivado a isso, Vladimir Putin resgata não apenas o uso da geoestratégia, mas a fundamenta conforme a lógica eurasiana, enaltecendo seus objetivos de dar extrema importância à região da Eurásia, assim como de solidificar a identidade russa em resposta à expansão ocidental em nova ordem mundial.

A inserção russa na Síria é parte disso. Ao chamar a atenção do mundo ao estender-se sem consenso mesmo com impactos negativos cada vez maiores, o Estado sírio é apoiado pela Rússia em diversos âmbitos devido à sua importância para o país, principalmente considerando sua relevância geopolítica, justificando assim a inserção russa.

Assim, trabalha-se com a hipótese de que a inserção russa no caso sírio é uma jogada puramente geopolítica, dando-se como uma reação contra uma ordem mundial ditada eminentemente por um poder ocidental. Desta maneira, a manutenção do governo de Bashar Al-Assad é (geo)política e economicamente imprescindível para a Rússia manter a balança de poder na região. Vale pontuar que não se busca fazer um aparato detalhado da crise síria em si, mas sim das motivações russas, ou seja, o que faz com que a Rússia apoie o regime de Bashar al-Assad? Quais os objetivos que

Thainá Penha Baima Viana Nunes - Mestranda no Programa de Pós-Graduação em Relações Internacionais na Universidade Federal de Uberlândia;

Mayane Bento Silva - Doutoranda em Relações Internacionais pela Universidade de Brasília. 
esta nação busca se colocando em uma posição tão sensível no sistema internacional?

A pesquisa desenvolveu-se por meio da consulta a fontes primárias e secundárias, em especial artigos científicos, dando espaço também para noticiários propícios à atualização da pesquisa com fatos recentes. Foi dada prioridade para escritores inseridos na política russa, a fim de demonstrar a visão russa da inserção, e não a ocidental.

Conclui-se que a participação russa no conflito da Síria, atuando para manutenção do governo do presidente Bashar al-Assad, é, em termos teóricos, um desdobramento da retomada do primado da geopolítica russa, definida como neo-eurasiana, e, em termos geopolíticos, é motivada pelos vínculos históricos entre Rússia e Síria, aos interesses russos de acesso ao Mar Mediterrâneo no porto de Tartus e à manutenção da balança de poder na região em face da crescente ameaça do Ocidente.

\section{A RECONSTRUÇÃO DA GEOPOLÍTICA}

A partir do século XIX, a geopolítica do sueco R. Kjellén, do inglês H. Mackinder, do general-geógrafo alemão K. Haushofer e do norte-americano A. Mahan consolidou-se como um comodismo vocabular, que como "nova ciência” serviu muito mais aos interesses dos Estados coloniais na Europa e por isso tornou-se famosa nos círculos de poder tanto na Europa fascista quanto nos ambientes militares do terceiro mundo, a exemplo da influência do determinismo alemão em Mario Travassos, Everardo Backheuser, Golbery, Meira Matos e Lysias Rodrigues no Brasil (Costa 2013).

Costa (2013) busca esclarecer as distinções entre geopolítica e geografia política a partir de uma postura crítica. Para o autor, a geopolítica representa um inquestionável empobrecimento das análises geográfico-política de Bowman, Camille Vallaux, Ratzel Hartshorne e outros e diferentemente de como Kjellén tentou posicioná-la, para Costa (2013), a geopolítica surge como um "reducionismo técnico e pragmático da geografia política, na medida em que se apropria em parte de seus postulados gerais para aplica-los na análise de situações concretas interessando ao jogo de forças estatais projetado no espaço" (Costa 2013, 55).

Até os anos 1970, a geopolítica passou por uma crise considerada divisor de águas. Além da superação da sua fama como instrumento da Alemanha nazista, com o advento da globalização, o Estado nacional moderno se enfraqueceu, e, consequentemente, a Geopolítica se viu sem a sua principal base de estudo (Vesentini 1997; Black 2009). Somado a isso, a terceira revolução industrial, técnico-científica, e o surgimento das novas tecnologias fizeram com que a democracia avançasse de vento em popa; as 
fronteiras nacionais se dissolvessem, e; novos atores surgissem para consolidar a nova ordem mundial (Vesentini 1997).

'Sob a influência da 'geografia crítica' francesa - em particular Yves Lacoste e seu grupo em torno da revista Hérodote - já se registram tentativas de 'recuperar' a geopolítica, emprestando-lhe caráter distinto daquele da sua 'fase maldita”" (Costa 1992 apud Horta 2006, 56). Uma interpretação epistemológica mais cuidadosa revela que tanto a geografia política quanto a geopolítica produziram conhecimentos comprometidos com a dominação de povos e territórios, mas também construíram trabalhos críticos e reflexivos em relação aos Estados e suas políticas internas e externas.

Desta maneira, a partir dos anos de 1980, os movimentos de tentativa de recuperação da Geopolítica foram sentidos nos Estados Unidos e na Europa (com destaque especial para a França). O resultado dessa reestruturação é chamado de “'segunda vaga’ da geopolítica”, e caracteriza como "menos ambiciosa nas pretensões científicas e mais cuidadosa com sua fundamentação epistemológica” (Fernandes 2010, 34).

A discussão é impulsionada quando se aborda o cenário da Geopolítica à época da Guerra Fria, afirmando que a incerteza das reais capacidades dos dois blocos, capitalista e socialista, trouxeram graves problemas aos analistas. Afinal, vivia-se a altercação de uma possível guerra nuclear entre ambos. Além disso, há de se considerar que essas tecnologias não foram utilizadas; logo, não havia uma maneira de medir sua real efetividade (Black 2009).

A partir dos anos 1990, com fim da Guerra Fria, a reestruturação da Geopolítica passou a ser notada com mais veemência, pois o mundo deixava de ser bipolar e passava a ser unipolar, tendo os Estados Unidos como hegemonia. A movimentação para uma nova ordem mundial trouxe sérias discussões do que deveria ser a Geopolítica dali para frente, devendo-se considerar agora não só o Estado, mas também as diversas relações e atores que surgiriam.

Principalmente após o ataque teorista de 11 de setembro vivido pelos Estados Unidos, a intenção geopolítica a partir de então era travar uma luta contra o islamismo ocidental por meio do que Bush nomeou "guerra ao terror”. Importante ressaltar, porém, que a reconstrução proposta pelos Estados Unidos e aceita pela parcela ocidental do mundo não o era pela parcela oriental, afinal, os primeiros buscariam a partir dali implementar de maneira universal o seu modelo de democracia, como nas tentativas no Iraque e no Afeganistão (Black 2009).

Essa visão foi refutada por Huntington, ao considerar que os conflitos a partir daquele momento passariam a ser entre civilizações, o que cooperaria para o declínio do Ocidente (Black 2009) e a consequente indefinição de 
uma nova ordem mundial. Questões como a de civilizações e identidade se somariam a outras, como as relativas à segurança internacional, a recursos energéticos, a conflitos de caráter intraestatal e diversos outros problemas de soluções cada vez mais inalcançáveis em nível global (Bonfim 2005). Assim, tornava-se cada vez mais patente a importância das análises da relação entre poder e território concernentes aos estudos geopolíticos.

Todo esse arcabouço passou a ser fortemente considerado na Rússia pós-Guerra Fria por diversos teóricos geopolíticos. Importante destacar Aleksandr Dugin como principal influenciador da geopolítica russa atual, tendo desenvolvido uma nova territorialidade para o Estado. Desta maneira, é considerado "um comentarista polêmico com uma conta assertiva do espaço nacional e os supostos imperativos biológicos da nação” (Black 2009, 174).

\section{RENASCENDO DAS CINZAS: A REESTRUTURAÇÃO RUSSA PÓS-GUERRA FRIA}

Após o fim da União Soviética, a Rússia passou por um momento delicado em todos os âmbitos, tendo assim a Rússia perdido o status de grande potência e cativado o novo status de potência nuclear regional. Após o desmantelamento da União Soviética, a Federação teve grandes perdas. Dos dados calculáveis, considera-se que houve a perda de $50 \%$ de sua população, $40 \%$ da capacidade industrial e 30\% do território (Trenin 2001), porém, muito foi perdido em essência subjetiva, sendo assim incalculável.

Desde então, houve três presidentes da Federação Russa com abordagens muito diferentes, tendo os dois últimos um alinhamento mais claro. $\mathrm{O}$ primeiro deles, Boris Yéltsin, esteve de 1991 a 1999 no poder. Ele assumiu em meio a uma crise geral na Rússia, proveniente do fim de seu sistema comunista. Assim, vivia-se uma crise política, cultural, econômica e principalmente identitária, o que se tornou uma grande barreira para o governo por não compreender com clareza qual posição a Rússia deveria ter a partir de então, principalmente no que tange à sua ideologia (Cidob 2010).

Tendo este cenário como plano de fundo, Yéltsin dispôs como objetivos prioritários diplomáticos a segurança do espaço que antes ocupava a União das Repúblicas Socialistas Soviéticas (URSS) e o impedimento da expansão da área de influência da Organização do Tratado do Atlântico Norte (OTAN). Porém, o que se viu foi a prática de uma política pautada exageradamente na cooperação unilateral com os Estados Unidos, haja vista a ingenuidade de seu governo. A cooperação foi assim caracterizada devido ao Ocidente (tantos os Estados Unidos como a União Europeia) utilizar dessa aproximação para enfraquecer a Rússia, ao contrário de ajudá-la (Mazat e Serrano 2012). 
Essa parcela da história em que a Rússia se rende ao mundo unipolar foi chamada de "ilusão liberal", caracterizada por "uma grave crise cultural que, no âmbito da política externa, se definia como uma subserviência às potências ocidentais, as quais seriam vistas pelas lideranças políticas como avançadas e fontes de apoio a uma Rússia bárbara e atrasada” (Blum e Jacichen 2015,3).

A Era Putin ${ }^{1}$ chegou para modificar todo o cenário russo. No ano de 1999, Vladimir Putin assumiu o governo como presidente interino. Eleito, assume a presidência oficialmente no ano de 2000 e se depara com uma Rússia ainda desestabilizada devido à crise geral - política, social, econômica e identitária - ocorrida nos anos 1990. Por essa razão, busca implantar uma política baseada na reestruturação russa nos mais variados âmbitos (Blum e Jacichen 2015).

Com este objetivo, Putin reformou a política externa e a economia, tendo um crescimento do Produto Interno Bruto (PIB) de 7\% ao ano, de 1999 a 2008. Com a significativa recuperação da economia russa, a política externa também foi reformulada, considerando sua independência ocidental e fazendo, assim, com que o maior objetivo da política externa russa pudesse ser colocado em prática: a busca da reafirmação de seu poderio como grande potência no sistema internacional.

Esse sentimento traz consigo outro ponto: para que seja exercido o poder, a Rússia precisaria, primeiramente, definir a área em que esse poder seria executado, ou seja, sua zona de influência, podendo assim exercer sua segurança estatal e maximizar o poder na região estrategicamente traçada (Adam 2011), sendo essa zona entendida por todo o espaço pós-soviético.

Isto posto, a política externa do primeiro mandato de Putin é caracterizada como multiconvencional e multipolar e afirma que "a Rússia almeja uma política externa equilibrada onde a procura de polos múltiplos visa diversificar aliados e permitir a alteração de relações privilegiadas numa constante procura de contrapeso e primazia” (Freire 2009, 12). Enquanto isso, internamente, a Rússia vivia uma estabilidade e crescimento econômico, o que ajudou a garantir aos demais âmbitos da política russa a sensação de independência e autoconfiança do novo papel que buscaria a partir de então, regionalmente e globalmente, por meio da Comunidade de Estados Independentes (CEI) e da dimensão oriental.

O hiato Medvedev, de 2008 a 2012, preocupou-se, basicamente, em dar continuidade às políticas instauradas por Vladimir Putin, ainda muito influente como Primeiro Ministro. Medvedev assumiu em meio a uma queda do $\mathrm{PIB}$ de $-7,9 \%$ devido à crise econômica de 2009 , o que o levou a abrir o país para o capital estrangeiro a fim de dar chances ao desenvolvimento do setor privado. Alguns autores defendem que esta seria a principal di- 
vergência entre o governo de Putin e o de Medvedev, porém, a abertura da economia russa em meio à crise não foi assim tão distante do que faria Putin se estivesse na presidência (Segrillo 2011).

Assim, pode-se afirmar que Medvedev teve como objetivo principal da política externa de seu governo "a integração da Rússia com a comunidade internacional em pé de igualdade e respeito com a OTAN e a UE, mas sem deixar de levar em conta o pragmatismo na política internacional, baseado no acatamento dos interesses nacionais da Federação Russa” (Cidob 2010, 498, tradução nossa).

O mandato de Medvedev foi visto como uma tentativa de aproximação sutil do Ocidente, tanto no que tange aos Estados Unidos, à época com o presidente Obama à frente, quanto à União Europeia, a qual aceitou concretizar acordos como a "Associação para a Modernização" que visava a superação do atraso tecnológico russo (Segrillo 2011).

O pragmatismo de Putin continuou a ser levado em consideração por Medvedev, o qual ampliou o campo de política externa para relações multilaterais, inclusive com o ocidente, como meio de estar mais próximo do "inimigo" capaz de fazer desandar seus objetivos geopolíticos, de estarem próximos da zona estratégica referente à CEI. Ao retornar ao poder como presidente da Rússia, Vladimir Putin adicionou novos objetivos à política externa, no Conceito de Política Externa da Federação Russa de 2013.

\section{GEOPOLÍTICA RUSSA NA ERA PUTIN: O NEO-EURASIANISMO}

Com os novos desafios trazidos à herdeira soviética após o fim da Guerra Fria, quatro grupos se esforçaram para construir e defender maneiras de reestruturação da Federação: os pró-ocidentais, que defendem o mundo unipolar com obediência e adaptação aos ideais dos Estados Unidos, posicionamento este colocado em prática no governo Yeltsin; os liberais moderados, que utilizavam uma corrente realista a fim de desenvolver uma política externa russa distinta; os conservadores moderados, que não entendiam o fim da URSS como o fim de uma grande Rússia mas sim como a necessidade de desenvolvimento de sua influência nas regiões de seu interesse e diminuição da dependência do Ocidente, e; esquerda e direita radicais, que buscavam meios bruscos de reconstruir o status de grande potência da Rússia (Kerr 1995).

Apesar do esforço geral, a escola Neo-Eurasiana foi a que mais ganhou ênfase na política russa desde o início do presente século. Dentre as suas diferentes perspectivas carregadas por nomes como Evgenii Primakov, Gennadii Ziuganov e Aleksandr Dugin, entende-se que este último tem maior aplicabilidade, haja vista sua relevância para estudos geopolíticos, as- 
sim como seus esforços para institucionalizar sua contribuição dentro e fora da Federação por meio da criação do Partido Eurasiano e do Movimento Eurasiano Internacional, respectivamente. (Segrillo 2013; Bassin 2015).

As variações do Eurasianismo não podem ser reduzidas a uma só por existirem em contextos políticos e agendas ideológicas muito distintas, porém, há de se considerar dois princípios comuns: "o Eurasianismo em toda parte reivindica representar uma síntese única dos princípios europeus e asiáticos, e nos dias de hoje, reivindica em todo lugar ser o legítimo herdeiro do legado “clássico”" (Bassin 2015, 281, tradução nossa).

O conceito é definido como "corrente ideológica e sociopolítica nascida dentro do ambiente da primeira onda de imigração russa, unificada pelo conceito de cultura russa como um fenômeno não-europeu, e apresentando uma combinação original de características ocidentais e orientais" (Dugin 2014, 17, tradução nossa). Assim, valoriza o espaço geográfico como de grande importância para a construção da história e cultura de seu povo, evitando importar quaisquer modelos de Estado existentes e criando o seu próprio.

Berryman (2012) assume que o Eurasianismo foi primeiramente invocado como uma ferramenta de manutenção do poder russo. Dugin (2014, 20), por sua vez, afirma que entre as metas do Eurasianismo estavam: manter "riqueza e prosperidade, um estado forte, uma economia eficiente, um exército poderoso e o desenvolvimento da produção" (tradução nossa). Com estes controles, o Estado russo poderia realizar seus ideais mais fortes e seus nomes importantes deveriam defender, fortalecer e preservar todo o arcabouço ideológico eurasianista.

O Neo-Eurasianismo, por sua vez, é descrito como uma corrente "que consiste no renascimento dos princípios clássicos do movimento em uma fase histórica qualitativamente nova e na transformação desses princípios em alicerces de um programa ideológico e político e de uma visão de mundo" (Dugin 2014, 30, tradução nossa). Sua versão se propôs a conservar pressupostos básicos do Eurasianismo clássico, desenvolvendo conceitos como o de civilização, da crítica à civilização romano-germânica, do fator espacial, da plataforma política, da tese de demotia e da tese da ideocracia (Dugin 2014). Nota-se que em nenhum momento a ênfase da necessidade russa de preservar-se da possível importação do modelo Ocidental de Estado, assim como a manutenção da rejeição do Ocidente em seus objetivos geopolíticos, é deixada de lado.

Em comum entre o Eurasianismo clássico e sua versão Neo está a definição da civilização Eurásica de acordo com seus pontos de contrastes com o Ocidente. Tendo este último apresentado atos hostis à geopolítica russa durante a história, é por isso considerado o maior desafio da corrente desde 
seu nascimento clássico nos anos de 1920. Importante considerar que, neste contexto, o líder atlantista são os Estados Unidos: "os Estados Unidos estão atualmente se esforçando para consolidar sua dominação global, como indicado, e é ao mesmo tempo o imperativo geopolítico e o destino geopolítico da Rússia-Eurásia o de liderar o resto do mundo em resistência a isso" (Bassin 2015, 290, tradução nossa).

Afim de dar continuidade às contribuições de Lev Gumilev, Dugin transformou o pensamento eurasiano em ato político a partir de 1990, buscando ir muito além da ideia instaurada por Nikolai Trubetzkoy, ainda no século XIX, de que o Eurasianismo se concentrava em mostrar que a Rússia não se entendia como um território europeu, nem mesmo asiático, mas sim como eurásico, e que a isso deveria ser dado valor e importância (Dugin 2014).

Assim, Dugin sugere uma nova teoria, em que o mundo seria dividido em quatro: Eurásia, América, Euro-África e Ásia-Pacífico. Todas essas regiões seriam baseadas em princípios igualitários, assim como se reconheceriam mutuamente, sendo o mundo policêntrico para superar a ameaça de uma hegemonia estadunidense (Bassin 2015).

Ao abordar a geopolítica da Rússia contemporânea, é afirmado com veemência que a geopolítica clássica cede à geopolítica russa todo o suporte necessário para a sua formulação fundamental. Para justificar sua afirmativa, volta à geopolítica clássica, na Heartland de Mackinder, afim de apresentar a base telucrática da geopolítica russa, ou seja, o poder terrestre russo, construído desde o século XV (Dugin 2016a).

Desde este século, paira na geopolítica russa um objetivo principal que baseou a Federação em todos os momentos, independentemente da divergência entre eles: "a integração da Heartland, o fortalecimento da sua influência na zona Norte da Eurásia, a afirmação da sua identidade perante o seu adversário mais agressivo, a Europa Ocidental (...), que aceitara a iniciativa da 'civilização do Mar' e da talassocracia” (Dugin 2016a, 263).

Assim, há três deduções necessárias à geopolítica russa: necessidade constante de afirmação da soberania estatal; recorrentes conflitos com a civilização do Mar, e; o entendimento de que a influência russa vai muito além das fronteiras delineadas (Dugin 2016a). Há de se notar, portanto, que essas três deduções são facilmente encontradas na política externa atual da Rússia, assim como podem ser percebidas em seu período de União Soviética e anteriores.

$\mathrm{O}$ apoio de Yevgeny Primakov, então primeiro ministro russo, à corrente Neo-Eurasiana, deu a Dugin a oportunidade de se destacar a partir de 1999, ao se tornar assessor de Gennadiy Seleznyov, presidente da Duma Estatal, que por sua vez exigiu que os escritos geopolíticos de Dugin pas- 
sassem a fazer parte da educação escolar. Com a criação do Movimento Internacional Eurasiano, no ano 2000, aumentou seu networking ao conquistar a participação de grandes nomes, como o vice-speaker do Conselho Federal da Rússia Aleksandr Torshev. o assistente do presidente Aslambek Aslakhanov e o presidente do Comitê Internacional do Conselho da Federação Russa, Mikhail Mangelov (Shekhovtsov 2008).

Nos anos seguintes, tendo Putin sido eleito, a geopolítica eurasiana de Dugin passa a ser implementada lentamente, como forma de inserir a Rússia no sistema internacional, construindo um novo momento de glória dos ex-soviéticos (Sousa 2012). Paralelo a isso, Dugin consegue aumentar seu espaço de influência quando passa a fazer parte do Centro de Perícia Geopolítica, e quando Ivan Demidov, seu admirador declarado, passa a ter papel chave na política russa (Shekhovtsov 2009).

A retomada da geopolítica enquanto prática de dominação territorial, executada primordialmente pela Rússia de Putin, busca restabelecer o controle do país sobre o território eurasiano por meio da elevação da importância da cooperação com os países que fazem parte do Exterior Próximo. Assim, após o vácuo geopolítico dos governos anteriores, Putin buscou fortalecer a figura da Rússia em seu novo eixo geopolítico, buscando alianças como a realizada em conjunto com a China, o Cazaquistão, o Quirguistão, o Tadjiquistão e o Uzbequistão em 2001, a Organização para Cooperação de Xangai, construída "sobre uma lógica multipolar e orientada inequivocamente para indicar um possível formato de oposição estratégica ao mundo unipolar e à exclusiva hegemonia americana” (Dugin 2016a, 117). Prova disso é a afirmação de que houve a intensificação da internacionalização do movimento Eurasianista na região ex-soviética a partir de 2003, quando os membros da Comunidade de Estados Independentes (CEI) mostraram compartilhar dos valores Neo-Eurasianistas, fazendo com que passasse a existir bolsões do movimento Eurasianista tanto no Exterior Próximo como muito além dele:

Estruturas organizadas do Movimento Eurasianista no exterior passaram a existir no Cazaquistão, Bielorrússia, Tajiquistão, Quirguistão, Ucrânia, Azerbaijão, Armênia, Geórgia, Bulgária, Turquia, Líbano, Itália, Alemanha, Bélgica, Grã-Bretanha, Espanha, Sérvia, Polônia, Eslováquia, Hungria, Canadá e Estados Unidos (Dugin 2014, 28, tradução nossa).

Como forma documental oficial do Estado Russo, buscou-se a Concepção de Política Externa de 2016, último documento desta natureza emitido até então. Nele pode ser notado que a Rússia não se considera um Estado pequeno, tampouco insuficientemente influente. Em sua terceira meta é afir- 
mado que se busca "consolidar a posição da Federação Russa como o centro de influência no mundo atual” (Rússia 2016, 1, tradução nossa). Em outros momentos, o documento mostra que a Federação tem uma leitura da nova ordem mundial como multipolar, em que os Estados devem sempre obedecer à legalidade da Organização das Nações Unidas (ONU).

No entanto, não poderia deixa de ser pontuado um dos seus maiores inconvenientes, que é também peça chave na teoria Neo-Eurasiana. O anti-atlantismo é inserido nos documentos, ainda que de maneira discreta, como forma de oficializar discursos provenientes de casos que envolveram a Rússia e o Ocidente. Na Concepção de Política Externa de 2013, antecessora da de 2016, há a afirmação de que "a habilidade do Ocidente de dominar a economia e política do mundo continua a diminuir” (Rússia 2013,2) paralelo ao crescimento dos países da Ásia-Pacífico.

Na Concepção de 2016, o recado se dá de forma um pouco mais objetiva e concreta:

As tentativas feitas pelas potências ocidentais para manter suas posições no mundo, inclusive impondo seu ponto de vista sobre os processos globais e conduzindo uma política para conter centros alternativos de poder, levam a uma maior instabilidade nas Relações Internacionais e crescente turbulência nos mercados globais e níveis regionais (Rússia 2016, 2, tradução nossa).

Em outro momento, sobre a Organização do Tratado Atlântico Norte (NATO, na sigla em inglês), organização que tem como "líder" os Estados Unidos:

A Federação Russa mantém sua perspectiva negativa em relação à expansão da NATO, à infraestrutura militar da Aliança se aproximando das fronteiras russas e sua crescente atividade militar nas regiões vizinhas da Rússia, considerando-as uma violação do princípio de segurança igual e indivisível e levando ao aprofundamento das antigas linhas divisórias na Europa e ao surgimento de novas (Rússia 2016, 13, tradução nossa).

Ainda sobre a parcela ocidental, agora em relação aos Estados Unidos:

A Rússia acredita que o diálogo com os EUA sobre questões bilaterais e internacionais só pode avançar de forma estável e previsível quando conduzido em pé de igualdade, com base na confiança mútua, respeito pelos interesses de cada um e não interferência nos assuntos internos de cada um. A Rússia não reconhece a política dos EUA de jurisdição extraterritorial além das fronteiras do direito internacional e encontra tentativas inaceitáveis de exercer pressão militar, política, econômica ou qualquer outra, reservando o direito de responder 
com firmeza a ações hostis, incluindo o reforço da defesa nacional e tomar medidas retaliatórias ou assimétricas (Rússia 2016, 18, tradução nossa).

Desta maneira, fica mais fácil compreender em que sentido o NeoEurasianismo faz parte da política externa da Federação, ainda que não seja aplicada em seu completo arcabouço. Apesar disso, é evidente a contribuição da corrente de pensamento para a construção da nova Rússia pós-Guerra Fria, principalmente quando se olha para o governo de Putin.

Como nada está livre de críticas, Dugin é acusado de ser um "internacionalista travestido, devido à sua ênfase no bloco eurasiano continental no qual deve se inserir a Rússia” por muitos eslavófilos (Segrillo 2013, 57). Nesta mesma linha, o professor ucraniano Shekhovtsov (2008) busca provar em seus escritos que Dugin tem uma visão de mundo fascista, contrariando a maior parte dos autores utilizados para a produção deste artigo, que consideram as contribuições do mesmo muito relevantes para a reconstrução geopolítica da Rússia pós-soviética. Outros se juntam a ele ao discordarem da figura de Dugin:

Alan Ingram argumenta que os escritos de Dugin são caracterizados por "contradições e ofuscação que tornam seu trabalho um pouco resistente à interpretação convencional ou à sumarização coerente". [...] Paradorn Rangsimaporn caracterizou Dugin como um "camaleão político cujas opiniões se adaptam às circunstâncias atuais" (Shekhovtsov 2008, 3).

No decorrer de seu artigo, Shekhovtsov (2008) busca provar que as ideias de renovação do Eurasianismo propostas por Dugin são um mito, assim como a Nova Ordem Eurasiana por ele proposta, pois a sugestão de Dugin exigiria a existência de um regime totalitário em que a sociedade se subordinaria totalmente à política. Em artigo posterior, o mesmo autor defende que o Neo-Eurasianismo de Dugin é nacionalista, mais especificamente parte do movimento da nova direita que passa a tomar lugar em muitos países europeus: "Dugin tem uma influência significativa sobre a opinião pública na Rússia e está empurrando-a em uma direção de direita” (Shekhovtsov 2009, 707).

Em publicação mais recente, Shekhovtsov (2017) escreve sobre a crise Ucraniana e o envolvimento da Rússia à luz do Neo-Eurasianismo. Defende que, para derrotar seus inimigos atlantistas, a Rússia buscar construir um Império Eurasiano e, como parte disso, influenciaram "a insatisfação com as autoridades ucranianas, fortaleceram o movimento separatista pró-russo no leste da Ucrânia, alimentaram as tensões étnicas e sociais, lança- 
ram ações de desinformação e declararam centros políticos alternativos" (Shekhovtsov 2017, 186).

Independente da intenção de Dugin - que não é objeto deste artigo - buscou-se opiniões de vários autores para atestar a influência do autor como jornalista e comentarista político.

Portanto, o Neo-Eurasianismo implementado por Putin como base geopolítica pode ser notado em diversas reformas realizadas por Putin desde 2000, que levam à compreensão da importância da geopolítica eurasiana para a Rússia contemporânea: a reafirmação e recuperação da soberania da Rússia; a sustentação de seu território; a captura de oligarcas que atrapalhavam a evolução do Estado russo, seja exilando-os, seja encarcerando-os para pagarem por seus crimes; a comunicação autêntica com os Estados Unidos e com a Europa Ocidental, de maneira imparcial, buscando sempre vencer a tentativa de estabelecimento de uma ordem ocidental universal, mesmo que isso lhe custe todo o trabalho de unir forças para lutar a favor da multipolaridade; a adaptação de uma nova política que dê novas regras às mídias nacionais russas; a revalorização da história russa; o total suporte a todo e qualquer processo que integre seu Exterior Próximo; a regularização partidária sem lobbying, e; a consolidação da Federação Russa como poderosa em recursos energéticos (Dugin, 2016).

\section{GEOPOLÍTICA RUSSA E O CASO SÍRIO}

É imprescindível, ainda, deixar aqui traços da (geo)política russa quanto ao caso sírio, principalmente ao atentarmos que a Síria é um antigo amigo e aliado histórico russo desde o ano de 1946, quando assinaram o acordo secreto, conhecido como Acordo da Amizade. Em 1950, as relações entre os países se estreitaram com o a contribuição militar e econômica da Rússia à Síria. Por conta disso, apesar de não fazer parte do território soviético, a Síria se mostrou um entusiasmado aliado do bloco comunista, o que era de grande importância para os russos devido à posição geográfica da Síria no Oriente Médio (Picolli, Machado e Monteiro 2016; Trenin 2012b).

A edificação do poder da família Assad no governo, na década de 1970, só fez florescer a boa relação entre os países. A efetivação da base naval em Tartus, cedida pela Síria à então União Soviética em 1971, de localização geoestratégica, presenteou a Rússia com o acesso ao Mar Mediterrâneo.

Apesar do breve afastamento a partir da metade da década 1970, o Tratado de Amizade e Cooperação Sírio-Soviética se concretizou no ano de 1980, assegurando os apoios efetivados no início das relações entre ambos (Picolli, Machado e Monteiro 2016). A partir de 2005, Rússia e Síria, descontentados com o posicionamento unipolar estadunidense, uniram-se 
ainda mais contra o Ocidente. A Rússia, em particular, incomodava-se com a negligência dos Estados Unidos quanto ao poderio russo, deixando-a afastada de decisões globais importantes (Gama 2013).

Quando a Primavera Árabe ${ }^{2}$ atingiu a Síria, em 2011, com uma série de protestos sociais espalhados por todo o país e com manifestantes violentos e violentados pelo governo sírio, a crise logo se tornou uma guerra civil, o que levou os opositores ao governo a iniciaram o processo para desligamento do então presidente Bashar al-Assad do poder (Picolli, Machado e Monteiro 2016).

Logo, a crise na Síria ocorre a partir de manifestações da população local contra o regime de Assad, cobrando reformas constitucionais recusadas pelo governante (Zahreddine 2013). Sete anos depois, o conflito continua instaurado na região e já soma às estatísticas 511 mil mortos e milhões de refugiados sírios que buscam em outros países a sobrevivência (O Globo 2018). Diversos motivos são citados quando se estuda a questão para justificar a durabilidade do conflito: armas químicas do lado dos civis e do governo, o terrorismo do Estado Islâmico e os interesses dos outros Estados envolvidos no conflito, como a Rússia.

Paralelo à guerra civil síria, o assunto borbulha no cenário internacional. Estados Unidos, países vizinhos da Síria no Oriente Médio e a própria ONU proferiram críticas sobre o conflito. A partir daí, começaram a ser aplicadas sanções à Síria, de diversas direções do mundo, principalmente da União Europeia (UE) e dos Estados Unidos.

As sanções relacionavam-se principalmente com o bloqueio de contas efetivadas nos Estados Unidos de importantes nomes sírios como o próprio Bashar al-Assad e muitos de seus companheiros, assim como de fundos sírios no Banco Central Europeu. A proibição do acesso de sete pessoas ligadas a Bashar al-Assad ao bloco europeu também deve ser considerada, tal qual a implementação de algumas restrições ligadas ao comércio de metais, como o ouro. Regionalmente, houve o banimento da Síria da Liga Árabe, encabeçada pela Arábia Saudita (Paiva e Fernandes 2012).

Não demorou muito para o assunto ser debatido dentro da ONU, a fim de encontrar soluções para o conflito sírio. Em setembro de 2011 foi aprovada uma missão para investigar casos de violação de Direitos Humanos naquele país. Houve também a tentativa da aprovação de algumas resoluções no Conselho de Segurança, as quais foram duramente criticadas pela Rússia, com posterior veto (Gama 2013). Este caso ocorreu no Conselho de Segurança da $\mathrm{ONU}$, relativo às propostas de resolução para intervenção no conflito sírio, encabeçadas por países como Marrocos e Arábia Saudita, por meio da Liga Árabe, assim como europeus, tais como França e Inglaterra (Paiva e Fernandes, 2012). Desta maneira, consideram-se os vetos russos 
no âmbito da ONU e o apoio russo ao governo de Bashar al-Assad diretamente alinhados com os interesses geopolíticos da Rússia.

Utiliza-se, portanto, a base do pensamento Neo-Eurasianista para justificar a inserção da Federação Russa no conflito sírio. O que se mostra como o principal objetivo desta corrente pode ser considerada a principal justificativa de tal inserção. Muitos autores buscam deixar bem claro que este objetivo geopolítico se refere à luta contra a inserção de um regime ocidental na Síria (Trenin 2012a; Trenin 2012b; Khlebnikov 2011; Dugin 2016b; Trenin 2016).

Na Concepção de Política Externa da Rússia de 2016, consta:

A Rússia representa um acordo político na República Árabe da Síria e a possibilidade de o povo da Síria determinar seu futuro com base no comunicado de Genebra de 30 de junho de 2012, declarações do Grupo de Apoio Internacional da Síria e resoluções relevantes do Conselho de Segurança da ONU. A Rússia apoia a unidade, a independência e a integridade territorial da República Árabe da Síria como um Estado secular, democrático e pluralista, com todos os grupos étnicos e religiosos vivendo em paz e segurança e desfrutando de direitos e oportunidades iguais (Rússia, 2016 16, tradução nossa).

Através dos fatos ocorridos pelo menos nos últimos 15 anos, podem ser notados os objetivos que motivam a inserção o Estado Russo na Síria. O interesse econômico, questões de energia nuclear, a base naval de Tartus e a considerável razão de que $90 \%$ dos armamentos sírios são provenientes da Rússia pesam na decisão de apoio à Síria; a luta contra movimentos terroristas no Oriente Médio, a inserção de parte do contingente militar russo na Síria e a necessidade de manutenção da influência na região também devem ser aqui considerados (Khlebnikov 2011; Trenin 2016).

Devem ser notadas as três deduções imprescindíveis à geopolítica russa, explanadas no tópico anterior. Enquanto aliada principal do governo de Assad, a Rússia se mostra soberana sob suas decisões, não se sentindo pressionada pelos Estados ocidentais e levando a sério a sua posição dentro do Conselho de Segurança da ONU; o conflito contra o que é chamado de civilização do mar, neste caso, se dispõe justamente à luta contra a hegemonia ocidental, logo, contra a implementação de seu poderio na região do Oriente Médio, seja por meio da União Europeia, seja por meio da OTAN, com ênfase na Síria, assim como no Exterior Próximo da Federação Russa, e; ao mesmo tempo, prova que a sua influência vai além das suas fronteiras, mostrando que seus limites não são delineados (Dugin 2016b). 


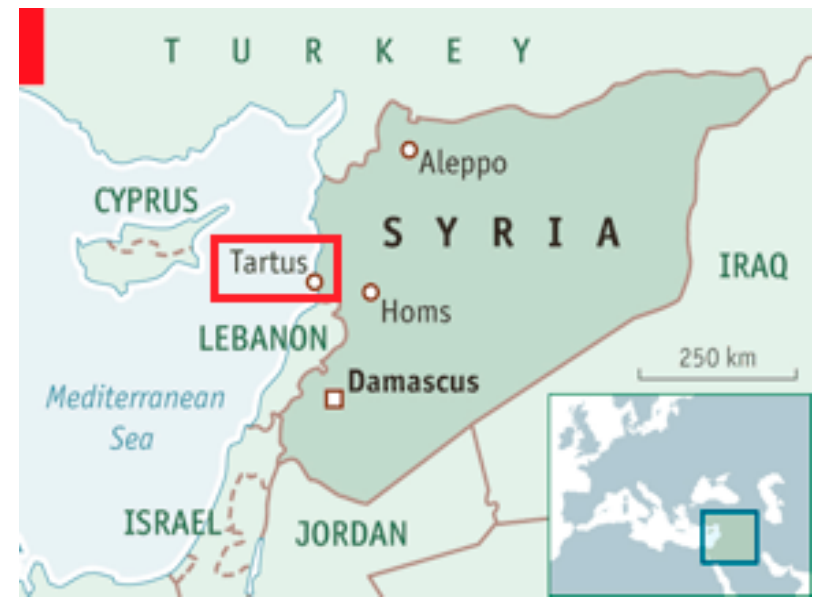

Mapa 1 - Localização da base naval russa em Tartus.

Fonte: <http://bit.ly/2nJmNmw>. Adaptado. Acesso em: 31 out. 2017.

Dentre os objetivos russos notáveis na Síria está a importância da base naval de Tartus. Essa permite à Rússia acesso ao leste do Mar Mediterrâneo (mapa 1), ou seja, assegura à Federação as linhas marítimas de comunicação. A presença da Rússia no Mar Mediterrâneo, assim como no Mar Negro, principalmente após a anexação da Crimeia ao seu território, faz com que a Rússia demonstre um poder latente na região, imensamente importante para a sua caminhada no rumo de se tornar novamente uma potência global:

Nota-se que o acesso ao Mediterrâneo Leste é de importância histórica para a Rússia, já que é através disto que se torna possível a ela demonstrar força, além de ser necessário para que Moscou mantenha uma postura de grande potência. O porto de Tartus é, portanto, a garantia de haver uma base na região no Mediterrâneo Leste, possibilitando à frota russa navegar e abastecer-se por ali. Esta questão configura-se, então, como um dos verdadeiros interesses russos por trás da Síria dentro do contex to de ela manter sua posição no Oriente Médio (Roberto 2012, 64).

Quanto à manutenção da influência russa na região, assim como manutenção da balança de poder regional, considera-se o fato de que Rússia e Síria sempre tiveram boas relações, sendo assim o apoio político nitidamente importante. A Rússia está em uma zona de conforto na Síria e a queda do governo de Assad significa para a primeira a possibilidade de perder 
sua influência na região, assim como perder a base naval de Tartus. Sua projeção de poder seria dissipada, o que afetaria diretamente seus objetivos geopolíticos. Tal manutenção é também referente à infraestrutura energética da região, citada como imprescindível para a Rússia, uma vez que sua economia é, em grande parte, pautada no setor energético. Há de se considerar, ainda, que a Rússia é fornecedora de energia para região, assim como a localização geoestratégica da Síria, a qual possui a Arábia Saudita como vizinha, essa última concorrente russa no mesmo setor (Roberto 2012).

Mais uma vez, deve ser enfatizado o posicionamento russo a partir da percepção do Ocidente como uma ameaça à luta pelo poder de potência da Rússia no sistema internacional. Como fortalecedor deste argumento está o próprio discurso do representante oficial da Federação Russa no Conselho de Segurança, Vitaly Churkin, no qual justificou os vetos russos às resoluções contra a Síria como forma de evitar a imposição de decisões ocidentais sobre os mesmos, extrapolando os poderes dados à ONU (Gama 2013).

A Rússia é peça imprescindível para que a Síria não entre em colapso. Caso ocorresse, suas consequências não seriam sentidas apenas na Eurásia, mas principalmente na Europa, levando para seu território milhões de refugiados. Isso faria com que houvesse uma desestabilização social, o que atrapalharia as políticas russas. Portanto, a inserção russa no conflito sírio deveria ser também de interesse europeu (Dugin 2016b).

No dia 13 de abril de 2018, um novo ataque foi realizado na Síria, mas dessa vez com uma novidade: Estados Unidos, França e Reino Unido se dispuseram a assaltar a soberania do Estado após suposto uso de armas químicas pelo governo sírio contra civis. Em uma reunião de emergência no Conselho de Segurança da ONU, a Rússia tentou aprovar uma resolução para punir Estados Unidos, França e Reino Unido pela invasão da soberania síria - sem sucesso. A posição russa não fugiu do esperado, pois buscou mostrar que o problema não estava no governo sírio, mas sim nos movimentos em oposição ao mesmo, financiados pelo Ocidente. Para tanto, Vasily Nebenzia, representante russo na reunião, citou Putin ao condenar o ataque precipitado ao território sírio, afinal, o relatório solicitado aos inspetores da Organização Independente para a Proibição de Armas Químicas (OPCW) ainda não tinha sido emitido para provar (ou não) que o governo sírio não fez uso de armas químicas (BBC 2018).

Analisando este caso, considera-se que os Estados Unidos, a França e o Reino Unido iniciaram uma guerra contra a Rússia e seus aliados. Essa "guerra" é puramente geopolítica, iniciada a partir do momento que o Ocidente percebeu que estava perdendo influência no local de ataque: 
Na Síria, a Rússia e seu aliado iraniano mudaram completamente o equilíbrio de poder no Oriente Médio, criando uma arquitetura da qual os atlantes simplesmente foram removidos. A Turquia hesitou e mudou-se cada vez mais para o eurasianismo. Portanto, não havia mais nada a fazer para resolver o assunto além da guerra. É a guerra dos atlantistas contra os eurasianos (Dugin 2018, tradução nossa).

Destarte, percebe-se que a Federação Russa possui uma agenda de política externa voltada para a geopolítica, considerando sua zona de influência, além de lutar diariamente de forma política com o Ocidente, no que tange aos Estados Unidos e à Europa, em suas decisões. Esse é um dos meios de a Rússia mostrar que tem capacidades de participar das decisões importantes e aumentar seu poder perante o sistema internacional, deixando de ser apenas uma potência regional e voltando ao status de potência global, como foi à época da URSS.

\section{CONSIDERAÇÕES FINAIS}

A transição que a Federação Russa sofreu desde o fim da União Soviética, considerando que nos anos de 1990 a Rússia viveu um período de conturbação constante com a perda de grande parte do seu território geográfico, não foi apenas trágica em si, mas significava devido aos custos político-ideológicos, econômicos e geopolíticos, visto que tudo que influenciava a geopolítica da União Soviética agora caía por terra, fazendo com que os presidentes que governaram a Rússia pós-soviética tivessem que buscar e concluir novos objetivos.

O governo de Boris Yéltsin e sua tentativa constante de alinhamento com o Ocidente colocou a Rússia em uma posição delicada no sistema internacional, afinal, não era segredo que o Ocidente buscava afogar ainda mais os ex-soviéticos em crise, apesar de disfarçadamente se portarem como amigo disposto a ajudar o outro a levantar-se depois de tanta devastação. Claramente, a política de Yéltsin não ajudou na recuperação da defasada Rússia, o que trouxe Vladimir Putin ao poder ainda em 1999, como presidente interino.

Em 2000 inicia a Era Putin, traçando os objetivos geopolíticos da Rússia baseado no Neo-Eurasianismo, o qual considera que a Rússia tem que ser grande por estar no coração da Eurásia, buscando assim se reestruturar como uma potência global.

Portanto, o apoio russo ao governo Sírio de Bashar al-Assad está consistentemente baseado nos objetivos eurasianos da geopolítica russa, considerando a boa amizade histórica existente entre Rússia e Síria; a luta 
contra a inserção do poder ocidental na região; a posição geoestratégica que possui o porto de Tartus para a Rússia como acesso ao leste do Mar Mediterrâneo, e; a manutenção da balança de poder na região, que influencia diretamente tanto na presença da Rússia no porto quanto no conforto por ali estar devido às questões energéticas relacionadas à vizinha Arábia Saudita.

Assim, a Rússia considera o envolvimento com a crise Síria uma oportunidade de colocar em prática alguns de seus objetivos pautados no eurasianismo, como o de diminuir o poder do ocidente, tomar o controle da zona de influência e conseguir uma saída estratégica para o mar, o que não deixa de ser uma maneira de expandir as suas fronteiras.

Por fim, conclui-se que o interesse russo no conflito sírio é primordialmente geopolítico, haja vista que sua política externa é totalmente pautada em questões que envolvem a luta contra o poderio do ocidente e o expansionismo de seu poder e zona de influência, sendo os custos para tal apenas um detalhe quando buscam seus reais objetivos.

\section{REFERÊNCIAS}

Adam, Gabriel Pessin. 2011. "A Rússia e os países da Comunidade dos Estados Independentes no início do século XXI”. In Uma Longa Transição da Rússia: Vinte anos de transformação na Rússia, editado por André Augusto de Miranda Pineli Alves, 40-80. Brasília: Ipea. http://www.ipea.gov.br/portal/index.php?option=com content\&view $=$ article\&id $=9014$.

Bassin, Mark. 2015. “Eurasianism 'Classical' and 'Neo': The Lines of Continuity. Bassin”. https://www.researchgate.net/publication/268300768_Eurasianism_ Classical_and_Neo_The_Lines_of_Continuity .

BBC. 2018. "Syria air strikes: US still 'locked and loaded' for new chemical attacks", Acesso em Abr 28, 2018. http://www.bbc.com/news/world-middleeast-43771840.

Berryman, John. 2012. "Geopolitics and Russian foreign policy". International Politics. 49 (4): 530-544.

Black, Jeremy. 2009. Geopolitics. London: Social Affairs Union. Kindle.

Blum, Gustavo Glodes e Julia Jacichen. 2015. "Em Busca de um Lugar na Nova Ordem Mundial: a Rússia, o Espaço Pós-Soviético e o Pensamento Geopolítico Russo". Geographia Opportuno Tempore 2 (1): 1-20. http://www.uel.br/revistas/ uel/index.php/Geographia/article/view/22794. 
Bonfim, Uraci Castro. 2005. "Curso de Política, Estratégia e Alta Administração do Exército". https://www.academia.edu/3068218/ CURSO_DE_POL\%C3\%8DTICA_ESTRAT\%C3\%89GIA_E_ALTA_ ADMINISTRA\%C3\%87\%C3\%83O_DO_EX\%C3\%89RCITO.

CIDOB. 2010. "Anuario Internacional CIDOB 2010: Federación Rusa, perfil de país”. CIDOB. http://www.cidob.org/es/publicaciones/serie_de_publicacion/ anuario_internacional_cidob/anuario_internacional_cidob_2010_federacion_rusa_perfil_de_pais.

Costa, Wanderley Messias da. 2013. Geografia Política e Geopolítica. 2. ed. São Paulo: USP.

Dugin, Aleksandr. 2014. Eurasian Mission: an introduction to Neo-Eurasianism. Budapeste: Arktos. Kindle.

Dugin, Aleksandr. 2016a. Geopolítica da Rússia Contemporânea. 3 v. Lisboa: Instituto de Altos Estudos em Geopolítica \& Ciências Auxiliares.

Dugin, Aleksandr. 2016b. Why we fight in Syria. German Center for Eurasianism Studies. http://germancenter.net/2016/12/09/alexandr-dugin-fight-syria/.

Dugin, Aleksandr. 2018. Wojna: powstrzymać ja czy reygrać? Geopolitica.ru, Abr, 15, 2018. https://www.geopolitica.ru/pl/article/wojna-powstrzymac-ja-czywygrac.

Ferabolli, Silvia. 2012. "Entre a revolução e o consenso: os rumos da Primavera Árabe”. Ciências \&̊ Letras (51). http://seer3.fapa.com.br/index.php/arquivos/article/viewFile/146/142.

Fernandes, José Pedro Teixeira. 2010. "Da Geopolítica Clássica à Geopolítica Pós-Moderna: entre a Ruptura e a Continuidade". In: Perspectivas geopolíticas: uma abordagem contemporânea, organizado por Charles Pennaforte e Ricardo Luigi. Rio de Janeiro: CENEGRI - Centro de Estudos em Geopolítica e Relações Internacionais.

Freire, Maria Raquel. 2009. "A política externa em transição: o caso da Federação Russa”. Relações Internacionais, (23): 75-89. http://www.scielo.mec.pt/scielo. php? script=sci_arttext\&pid $=$ S1645-91992009000300005\&lng $=$ pt\&nrm=iso.

Gama, Isabela. 2013. "As motivações russas para sua atuação na Síria: a identidade russa em questão”. Dissertação, PUC Rio. http://www2.dbd.puc-rio.br/perga$\mathrm{mum} / \mathrm{biblioteca} / \mathrm{php} / \mathrm{mostrateses}$.php?open $=1$ \&arqtese $=1111717 \_2013 \_$Indice. html. 
Horta, Célio da Cunha. 2006. "Geografia Política e Geopolítica: velhas e novas convergências”. Revista Geographia 8 (15).

Kerr, David. 1995. “The new Eurasianism: The rise of geopolitics in Russia's foreign policy”. Europe-Asia Studies 47 (6): 977-988.

Khlebnikov, Alex. 2011. "Why is Russia standing by Syria?". Tel Aviv Notes. https://dayan.org/content/tel-aviv-notes-why-russia-standing-syria.

Mazat, Numa e Frankling Serrano. 2011. "A Geopolítica da Federação Russa em relação aos Estados Unidos e à Europa: Vulnerabilidade, Cooperação e Conflito”. In: O Renascimento de uma potência? A Rússia no século XXI, editado por André Alves. Brasília: Ipea. http://www.ipea.gov.br/portal/index.php?option=com content\&view $=$ article\&id $=17334$.

O Globo. 2018. Em sete anos, guerra da Síria já tem mais de 511 mil mortos. $O$ Globo. https://oglobo.globo.com/mundo/em-sete-anos-guerra-da-siria-ja-temmais-de-5 1 1-mil-mortos-22479399\#ixzz5EHt9eSjx.

Paiva, Luciana e Márcia Fernandes. 2012 "Os vetos de China e Rússia no caso da Síria: interesses humanitários ou políticos?”. Conjuntura Internacional 3: 1-13. https://www.academia.edu/14013521/Os_vetos_de_China_e_Rússia_no_caso_ da_Síria_interesses_humanitários_ou_políticos.

Piccolli, Larlecianne, Lauren Machado e Valeska Monteiro. 2016. "A Guerra Híbrida e o Papel da Rússia no Conflito Sírio”. Rev. Bra. Est. Def. 3 (1): 189-203. https://rbed.emnuvens.com.br/rbed/article/view/63960/37927.

Roberto, Willian. 2012. "O Papel Russo na Crise Síria e sua Decorrência Internacional”. Revista Perspectiva (9): 57-72. www.seer.ufrgs.br/ RevistaPerspectiva/issue/download/2607/155\#page $=57$.

Russia. Concept of the Foreign Policy of the Russian Federation. 2013. http:// www.mid.ru/en/foreign_policy/official_documents/-/asset_publi

Russia. Foreign Policy Concept of the Russian Federation, 2016. http://www. mid.ru/en/foreign_policy/official_documents/-/asset_publi

Segrillo, Ângelo. 2011. "A Diarquia Putin-Medvedev: dimensões da Política Interna e da Política Externa”. In: Uma longa transição: vinte anos de transformações na Rússia, editado por André Alves André. Brasília: Ipea. http://www.ipea.gov.br/ portal/index.php?option $=$ com_content\&view $=$ article\&id $=9014$. 
Segrillo, Angelo. 2013. "Ocidentalismo, eslavofilismo e eurasianismo: intelectuais e políticos em busca da identidade russa". In: Intelectuais e modernidades, editado por Daniel Aarão Reis e Denis. Rio de Janeiro: FGV.

Shekhovtsov, Anton. 2008. "The Palingenetic Thrust of Russian Neo-Eurasianism: Ideas of Rebirth in Aleksandr Dugin's Worldview". Totalitarian Movements and Political Religions 9 (4): 491-506.

Shekhovtsov, Anton. 2009. "Aleksandr Dugin's Neo-Eurasianism: The New Right à la Russe. Religion Compass 3/4: 697-716.

Shekhovtsov, Anton. 2017. "Aleksandr Dugin's Neo-Eurasianism and the RussianUkrainian War". In: The Politics of Eurasianism: Identity, Popular Culture and Russia's Foreign Policy, editado por Mark Bassin e Gonzalo Pozo-Martin, 185-204. Lanham: Rowman \& Littlefield Publishers.

Sousa, Danilo. 2012. "A Nova Geopolítica Russa e o Eurasianismo”. Revista de Geopolítica 3 (2): 61-70.

Trenin, Dmitri. 2001. The End of EURASIA: Russia on the Border Between Geopolitics and Globalization. Washington DC: Carnegie Moscow Center.

Trenin, Dmitri. 2012a. "No return to the Past for Russia". The international Spectator 47 (3): 8-12. http://www.tandfonline.com/doi/pdf/10.1080/03932729. 2012.711677.

Trenin, Dmitri. 2012b. "Russia's Line in the Sand on Syria: Why Moscow Wants To Halt the Arab Spring". Foreign Affairs. https://www.foreignaffairs.com/articles/syria/2012-02-05/russias-line-sand-syria.

Trenin, Dmitri. 2016. "Russia in the Middle East? Moscow's objectives, priorities, and policy drivers". Carnegie Endowment for International Peace. http://ceip. org/2KpnmLM.

Vesentini, José. 1997. “O apogeu e o declínio da Geopolítica”. Revista do Departamento de Geografia, 11, 19-28. https://doi.org/10.7154/RDG.1997.0011.0002.

Zahreddine, Danny. 2013. "Crise na Síria (2011-2013): Uma Análise Multifatorial”. Conjuntura Austral 4: 6-23. http://seer.ufrgs.br/ConjunturaAustral/article/ view/43387. 


\section{NOTAS}

1. Considera-se Era Putin o período de 2000 até os dias atuais, afinal, a liderança e controle do regime russo foi administrado por Putin, quer como Presidente, quer como Primeiro-Ministro, sendo assim o mandato de Medvedev considerado apenas um hiato.

2. A Primavera Árabe foi uma onda de protestos que atingiu o mundo árabe a partir do ano de 2011. A insatisfação com a economia e com os regimes não democráticos fez com que grande parte da população árabe fosse às ruas com protestos pacíficos. Tal período é assim denominado por fazer menção à "Primavera de Praga" onde muitos, guiados por Alexander Dubcek, clamaram por reformas na economia e por liberdades individuais (Ferabolli, 2012). 


\section{RESUMO}

A ascensão da era Putin na Rússia vincula-se diretamente à retomada do primado da geopolítica nas relações internacionais do século XXI. Face a isto, busca-se identificar, a partir da perspectiva Neo-Eurasiana, as motivações geopolíticas da inserção russa no conflito sírio em resposta às ameaças que incidem na região.

Palavras-chave: Rússia; Síria; Neo-Eurasianismo; Geopolítica.

\section{ABSTRACT}

The rise of the Putin era in Russia is directly linked to the resumption of the primacy of geopolitics in international relations in the twenty-first century. In view of this, we seek to identify, from the Neo-Eurasian perspective, the geopolitical motivations of the Russian insertion in the Syrian conflict in response to the threats that affect the region.

Palavras-chave: Russia; Syria; Neo-Eurasianism; Geopolitics. 